including the types of both species, and dissected much of the material, he could find only male specimens of $L$. orca, and immature male and female $L$. scorpioides. This seemed to prove a classic case of sexual dimorphisn in Lebetus (and other gobies are known to be sexually dimorphic), and Miller's conclusion has been generally accepted.

The work of Demir and Russell, however, has shown that Lebetus cannot be dismissed as a monotypic genus, for in addition to the morphological differences they have demonstrated biological differences. Collections made in 1970 of young fish in the western English Channel revealed forty-two "Petersen type postlarvae" and more than four hundred of the "Fage type", and it was established that the Fage type were more abundant between February and August, whereas the former were found from June to September only. The 1970 survey also showed that Petersen pcstlarvae were most common inshore; the other form was caught only at offshore stations.

It now seems therefore that there are two Lebetus species in the European Atlantic. If Miller's view of $L$. orca as a synonym of $L$. scorpioides (the only two named forms in the genus) is correct, then clearly one of the forms described from postlarvae by Demir and Russell is so far unrecognized and unnamed as an adult. On the other hand, it may be that both $L$. orca and $L$. scorpioides are good species, and if so it is to the credit of the earlier workers, Collett, Petersen and Fage, that their observations have been supported by this recent work on the postlarvae of Lebetus.

\section{Puwr Patroloodr Host-Parasite Contact}

from a Correspondent

THE need for studies, on very short time scales, of the reactions arising from hostparasite contact was repeatedly stressed during a symposium on fungal pathogenicity and the plant's response, held at Long Ashton Research Station, University of Bristol, from September 22 to 24 .

In his inaugural lecture, Professor $\mathbf{R}$. K. S. Wood (Imperial College, London) emphasized the importance and specificity of the hypersensitive response (using the term in its botanical context). Originally applied to the death of cells in an incompatible relation between an obligate pathogen and a resistant host, it is now clear that the general concept may be more widely applicable. Of particular interest in this context was the demonstration by Drs A. Kaars Sijpesteijn and A. van Dijkman (TNO Biochemical Department, Utrecht) of the effect of two near-isogenic races of Cladosporium fulvum in causing leak- age from cells of two tomato cultivars, which showed complementary host-parasite reactions. Other contributions were devoted to the nature of the trigger system which initiates the biochemical and structural reactions that occur when a plant is challenged by a potential pathogen. The complexity of compounds implicated in disease resistance makes it difficult to resolve the sequence of cause and effect.

The intensive studies during the past 30 years on the role of ethylene were reviewed by $\mathrm{Dr}$ E. C. Hislop (Long Ashton Research Station) who drew attention to the possible implications of ethylene in altering the rate of disease development, and Dr Barbara Lund (Food Research Institute, Norwich) demonstrated that bacterial enzymes probably activate the production of ethylene by a route already present in normal tissue.

By original definition, phytoalexins are absent in the unchallenged host plant but the symposium suggested no such clear-cut distinction between preformed and induced resistance factors.

Because obligate pathogens cannot be grown in axenic culture, it is particularly difficult to examine the pathogen component of the host-pathogen system. The use of tissue culture has been of some value but, as shown by $\mathrm{Dr}$ D. S.
Ingram and Dr Inez Tommerup (University of Cambridge) with Peronospora farinosa on sugar beet callus tissue, it is not necessarily typical of the system in vivo. Electron microscopy has been increasingly used to study the structure of the host pathogen interfaces, where interchanges of nutrients, regulatory compounds, proteins, and perhaps even genetic material must occur. The participants were impressed by the elegance of such ultrastructural studies seen in the illustrations of Professor P. H. Williams (University of Wisconsin), Professor C. E. Bracker (Purdue University) and Dr L. J. Littlefield (North Dakota State University), Professor Williams showing how, in cabbage clubroot, the bullet-like "stachel" from encysted zoospores penetrate in a matter of seconds, but minutes are apparently required for the host to respond.

In his closing remarks, Professor P. W. Brian (University of Cambridge) considered that the present era of plant pathology has the same advancing frontiers as molecular biology and plant biochemistry. The study of host-pathogen interactions has not so far aided the chemical control of plant disease, but the symposium illustrated the delicacy of the balance of such interactions, better knowledge of which may lead to new ways of combating the pathogen.

\title{
Mutating the Rous Sarcoma Provirus
}

FURTHER evidence, if any were needed, that the replication of RNA tumour viruses involves a DNA replicative intermediate, the provirus, is reported by Bader and Brown in next Wednesday's Nature New Biology. These authors have exploited the reverse transcription of Rous sarcoma virus genomes to obtain mutants of this virus which are temperature sensitive for transformation. They argued that if chick cells are exposed to 5-bromodeoxyuridine, the mutagenic analogue of deoxythymidine, when they are infected with Rous sarcoma virus some BUdR should be incorporated into the DNA provirus as it is synthesized, presumably by the reverse transcriptase in the infecting virus particles. Furthermore, when the DNA proviruses containing BUdR residues in place of some of their thymidine residues are in turn transcribed to yield progeny RNA genomes, guanine for adenine base substitutions should be induced and some mutant progeny Rous genomes would be expected.

Bader and Brown found that if chick cells are simultaneously infected with Rous sarcoma virus and exposed to $B U d R$, but not if the exposure to BUdR is 12 hours before or 12 hours after infection, temperature sensitive progeny virus can indeed be isolated from the transformed cells some 24 hours after infection. Such progeny virus stocks transform chick cells more efficiently at $36^{\circ} \mathrm{C}$ than $40.5^{\circ} \mathrm{C}$, whereas the converse is true of wild type Rous sarcoma virus. This observation immediately suggested that many of the progeny virus particles liberated from the cells exposed to BUdR contain temperature sensitive lesions in the gene or genes responsible for transformation.

To prove this point, Bader and Brown isolated the progeny virus produced by 119 clones of cells transformed in the presence of BUdR and found that of these 20 yielded mutant virus temperature sensitive for transformation. Because BUdR is not metabolized into RNA by chick cells this result must mean at the very least that that part of the Rous sarcoma genome which determines the ability to cause the transformation of chick fibroblasts must be replicated by way of a DNA intermediate. Moreover, because cells transformed by these mutants at their permissive temperature and then shifted to the nonpermissive temperature continue to produce progeny virus, the temperature sensitive lesion cannot be interfering with the replication and packaging of the mutant genomes. 